\title{
Pembekalan Tentang Pentingnya Kualitas Jasa Bagi Siswa/i Kelas XI SMAK BPK Penabur Holis, Bandung
}

\author{
Christina Wirawan ${ }^{1}$, Melina Hermawan ${ }^{2}$, Raden Roro Christina ${ }^{3}$, \\ Stevani Irene Tatinting ${ }^{4}$, Karuna Adiarti Sutanto ${ }^{5}$ \\ \#1,2,3,4,5 Program Studi Teknik Industri, Universitas Kristen Maranatha \\ Jl. Prof. Drg. Surya Sumantri, MPh no. 65, Bandung 40164 \\ ${ }^{1}$ christina.wirawan@eng.maranatha.edu \\ ${ }^{2}$ melina.hermawan@eng.maranatha.edu \\ ${ }^{3}$ christina@eng.maranatha.edu \\ ${ }^{4}$ tatintingstevani@gmail.com \\ ${ }^{5}$ karunabeatbox@gmail.com
}

\begin{abstract}
Abstrak - Jasa adalah sesuatu yang sering ditemui dan dialami di kehidupan sehari-hari., dimana terkadang ditemukan kualitas jasa yang baik sehingga dapat memuaskan konsumennya ataupun kualitas jasa yang buruk sehingga dapat mengecewakan konsumennya. Seminar edukasi ini bertujuan untuk memberikan pembekalan tentang bagaimana pentingnya memberikan suatu jasa yang berkualitas tinggi dan memuaskan konsumen berdasarkan kepentingan dan kinerja dari sebuah jasa. Pembekalan materi tentang kualitas jasa merupakan satu pengenalan bagian mata kuliah Kualitas Jasa yang terdapat dalam kurikulum Teknik Industri. Pembekalan ini dilakukan secara daring dengan menggunakan aplikasi Zoom. Seminar yang dibawakan oleh para dosen dan dibantu oleh mahasiswa ini, terbagi dalam 2 (dua) sesi, yaitu pemberian materi tentang kualitas jasa dan studi kasus tentang kualitas jasa. Diskusi yang melibatkan peserta pun terjadi dimana siswa/i tersebut juga bercerita tentang kualitas jasa yang pernah dialaminya. Melalui pembekalan ini, diharapkan dapat memberi manfaat yang berarti bagi siswa/i dari SMAK BPK Penabur Holis, Bandung.
\end{abstract}

Kata kunci: kepentingan, kinerja, kualitas jasa, pembekalan

Abstract-Service is a thing that often met in daily life, whenever the service quality is found good and can satisfy the customers or bad that can dissapoint the customers. The aim of this educational seminar was to give knowledge of how important it was to give a high quality service quality and satisfy the customers based on the importance and the performance of a service. Material brief of the service quality is an introduction of the service quality subject on Industrial Engineering curriculum. This seminar was held online through Zoom application, delivered by lecturers and was helped by the students. This seminar, divided to 2 (two) sessions, which was material delivery and case study about service quality. The high school students participated in the discussion by telling their service quality experiences. Hopefully, through this brief, could be fruitful for the students of SMAK BPK Penabur Holis, Bandung.

Keywords: brief, importance, performance, service quality

\section{Pendahuluan}

Untuk memberikan kepuasan kepada konsumen, pelaku usaha harus mempelajari terlebih dahulu keinginan dan kebutuhan baik untuk saat ini maupun masa yang akan datang [1]. Untuk itu dibutuhkan suatu kemampuan untuk menggali keinginan dan kebutuhan tersebut agar keinginan dan kebutuhan tersebut dapat sesuai dengan harapan dari konsumen.

Perusahaan dituntut untuk dapat memuaskan pelanggannya dengan menciptakan produk atau jasa yang berkualitas sesuai dengan keinginan konsumen [2]. Jasa adalah sesuatu yang sering ditemui dan dialami di kehidupan sehari-hari., dimana terkadang ditemukan kualitas jasa yang baik sehingga dapat memuaskan konsumennya ataupun kualitas jasa yang buruk sehingga dapat mengecewakan konsumennya

Terdapat 5 (lima) dimensi dalam kualitas jasa yang harus diperhatikan bagi perusahaan yang bergerak dalam bidang jasa, yaitu reliability (keandalan), responsiveness (daya tanggap), assurance (jaminan), empathy (empati) dan tangibles (bukti fisik) [3]. Kelima dimensi ini harus dipenuhi untuk mendapatkan kepuasan konsumen, agar dapat memenangkan persaingan pasar. 
Semakin ketatnya persaingan berdampak pada peningkatan tuntutan konsumen dalam hal pelayanan [4]. Kepuasan pelanggan dipandang sebagai salah satu dimensi kinerja pasar [5].

Jika pelayanan yang diberikan melampaui harapan pelanggan maka kualitas pelayanan yang diberikan akan mendapatkan persepsi yang ideal dari para penerima pelayanan [6].

Kualitas pelayanan perlu mendapat perhatian besar dari perusahaan, karena kualitas pelayanan memiliki hubungan langsung dengan kemampuan bersaing dan tingkat keuntungan perusahaan [7]. Kunci keberhasilannya adalah membangun keunggulan bersaing yang berkesinambungan [8]. Tidak ada satupun bisnis atau organisasi yang dapat sukses tanpa membangun kepuasan dan keloyalitasan dari pelanggan [9]. Kualitas jasa yang buruk akan menyebabkan ketidakpuasan pengguna dan akan mengarahkan keterpurukan dari sebuah bisnis [10].

Tugas seorang dosen adalah memenuhi Tri Dharma Perguruan Tinggi, yaitu pengajaran, penelitian dan pengabdian pada masyarakat. Seorang dosen harus membagikan ilmunya kepada masyarakat agar dapat membangun masyarakat tersebut menjadi lebih baik. Dengan dasar itulah maka Program Studi Teknik Industri Universitas Kristen Maranatha beserta dosen-dosennya ingin mencoba untuk membagi ilmu kepada masyarakat luas.

Menyebarluaskan ilmu pengetahuan, teknologi dan seni dilakukan melalui fungsi pengabdian kepada masyarakat [11] .

Tujuan kegiatan Pengabdian Kepada Masyarakat ini adalah memberikan pelatihan dan pengenalan mengenai ilmu Manajemen Industri kepada siswa kelas XI SMAK BPK Penabur Holis, Bandung. Kualitas jasa adalah topik yang dipilih, karena setiap orang pasti mengalami pelayanan di dalam kehidupannya sehari-hari dan merupakan topik yang mudah dimengerti oleh orang awam.

Pemaparan ini memberikan pengenalan dasar mengenai ilmu service quality dalam kehidupan sehari-hari, terutama untuk menghadapi keunggulan kompetitif. Contohnya seperti menyetarakan harapan dan persepsi untuk kepuasan konsumen.

\section{METODE PELAKSANAAN}

Langkah-langkah dalam pelaksanaan kegiatan Pengabdian Kepada Masyarakat ini adalah sebagai berikut :

1. Persiapan pelaksanaan kegiatan

Pihak Program Studi Teknik Industri Universitas Kristen Maranatha berkoordinasi dengan pihak SMAK BPK Penabur Holis untuk mempersiapkan segala sesuatu yang dibutuhkan pada saat hari pelaksanaan kegiatan. Setelah mengetahui kebutuhan dari SMAK BPK Penabur Holis, maka Program Studi Teknik Industri Universitas Kristen Maranatha melakukan penugasan Kelompok Bidang Keahlian (KBK)
Manajemen Industri dan dosen-dosennya untuk pelaksanaan kegiatan tersebut.

2. Pelaksanaan kegiatan

KBK Manajemen Industri Program Studi Teknik Industri Universitas Kristen Maranatha melaksanakan kegiatan Pengabdian Kepada Masyarakat berupa seminar, kepada siswa kelas XI SMAK BPK Penabur Holis, Bandung dengan metode tatap muka secara daring via aplikasi Zoom. Pelaksanaan kegiatan ini terbagi menjadi 2 (dua) sesi. Sesi pertama dibuka dengan pemaparan materi berjudul "The Importance of Service Quality for Competitive Advantage". Lalu pada sesi kedua, dilakukan talk show dan diskusi dengan peserta mengenai studi kasus yang terjadi di kehidupan nyata sehari-hari jika dikaitkan dengan teori yang telah dibahas pada sesi pertama.

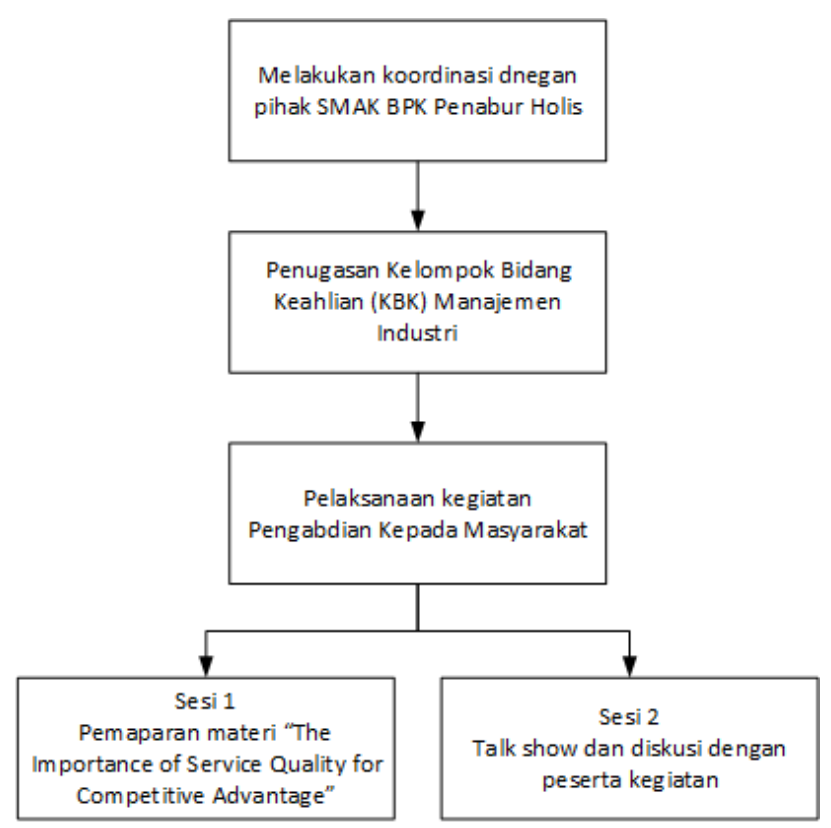

Gambar 1 Langkah-langkah Persiapan dan Pelaksanaan Kegiatan Pengabdian Kepada Masyarakat

\section{DISKUSI}

Sesi pertama dibawakan oleh 1 (satu) orang dosen, berupa pemaparan materi berjudul "The Importance of Service Quality for Competitive Advantage", di mana pada sesi ini dibawakan teori mengenai service quality, competitive advantage yang merupakan teori dari Porter, hubungan antara service quality, competitive advantage dan customer satisfaction. 


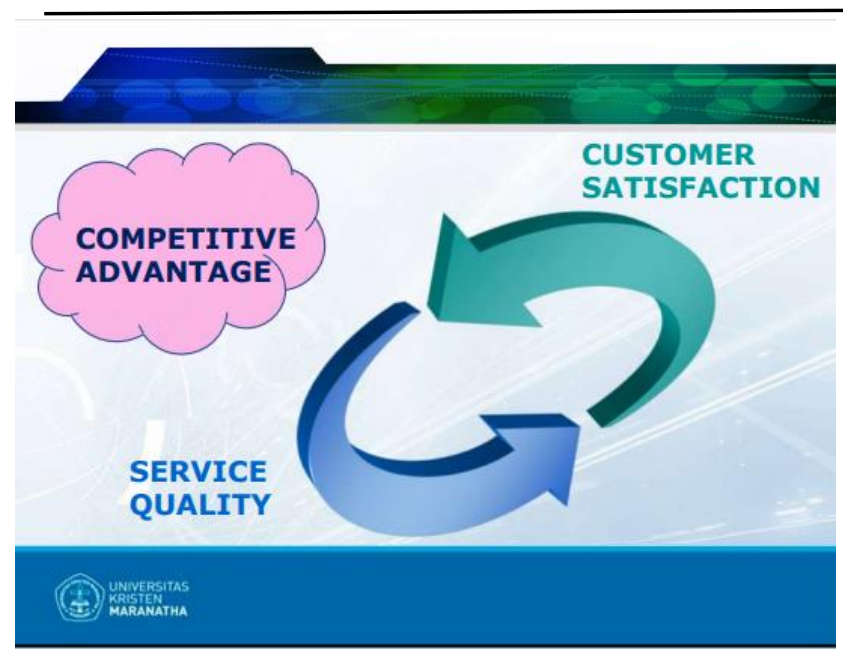

Gambar 2 Hubungan antara Competitive Advantage, Service Quality dan Customer Satisfaction

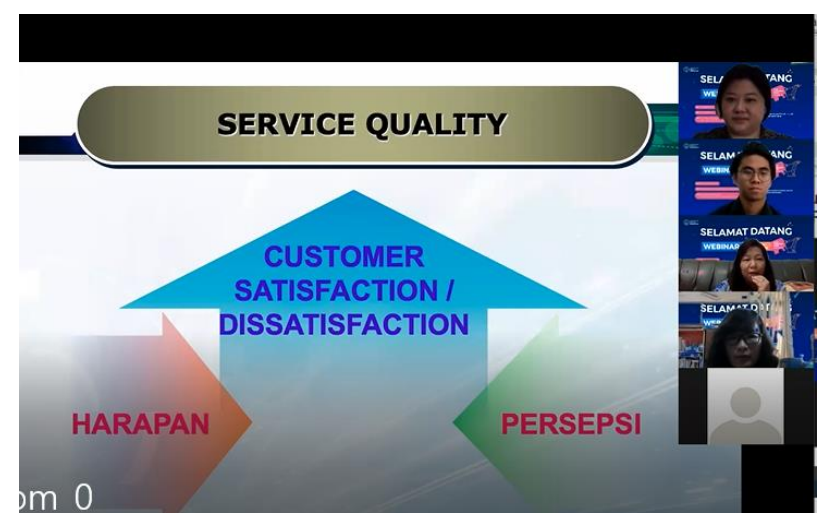

Gambar 3 Pemaparan Materi

Lalu pada sesi kedua, dilakukan talk show dan diskusi dengan peserta mengenai studi kasus yang terjadi di kehidupan nyata sehari-hari jika dikaitkan dengan teori yang telah dibahas pada sesi pertama. Para pembicara terdiri dari 2 (dua) orang dosen dan 2 (dua) orang mahasiswa.

Diskusi yang melibatkan siswa/i SMAK BPK Penabur Holis tersebut pun terjadi dimana siswa/i tersebut juga bercerita tentang kualitas jasa yang pernah dialaminya dan dilakukan pembahasan mengenai dimensi kualitas jasa mana yang mereka alami dalam studi kasus tersebut, jika disesuaikan dengan teori yang telah dipaparkan pada sesi pertama.

Baik pemaparan teori dan talk show berjalan lancar, interaktif dan hidup karena masing-masing bagian yang terlibat berperan serta secara aktif.

Siswa/i pun belajar akan pentingnya sebuah perusahaan untuk mementingkan kualitas dari jasa yang diberikan untuk memberikan kepuasan kepada konsumennya, sehingga perusahaan dapat memenangkan persaingan.

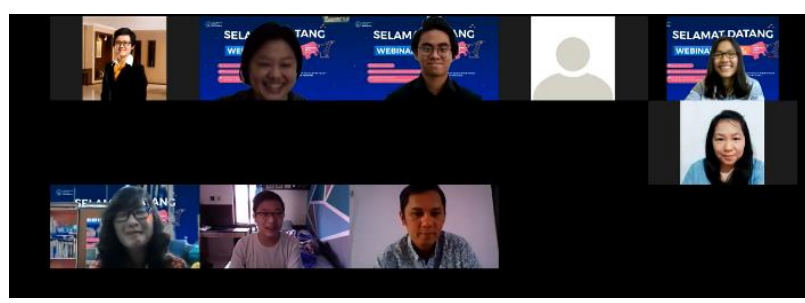

Gambar 4 Interaktif peserta dalam Talk Show

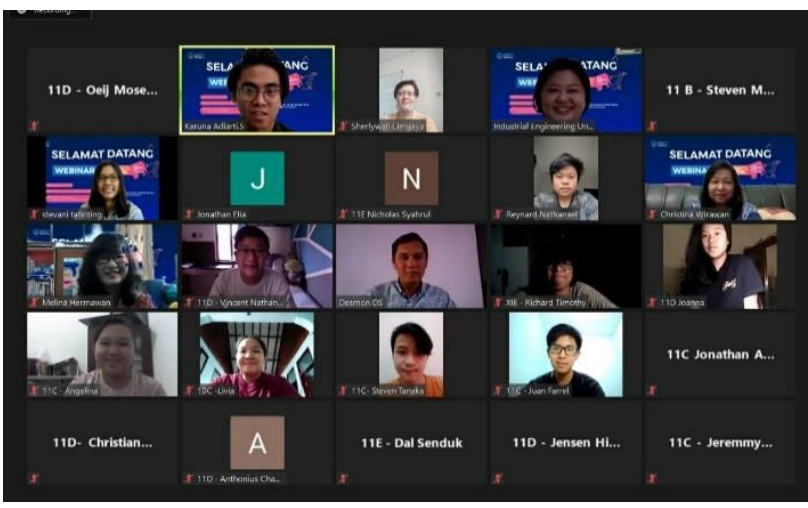

Gambar 5 Foto bersama Pembicara dan Peserta

\section{KESIMPULAN}

Dari hasil pembekalan yang telah dilakukan dalam kegiatan Pengabdian Kepada Masyarakat kepada Kelas XI siswa/i SMAK BPK Penabur Holis, Bandung diharapkan siswa/i dapat memahami tentang pentingnya kualitas jasa sejak dini.

Dengan membandingkan antara pengalaman yang dibahas dengan dibandingkan dengan teori yang telah dipaparkan, para siswa/i yang sangat antusias mengikuti setiap sesi dari kegiatan Pengabdian Kepada Masyarakat ini dapat belajar akan pentingnya sebuah perusahaan untuk mementingkan kualitas dari jasa yang diberikan untuk memberikan kepuasan kepada konsumennya, sehingga perusahaan dapat memenangkan persaingan.

Kegiatan seperti ini dapat berlanjut dengan memberikan pembekalan untuk topik-topik lainnya, seperti kepemimpinan dalam rangka memimpin diri sendiri maupun kelompok, kewirausahaan dan topik-topik lain yang cukup tepat untuk dibawakan kepada siswa SMA, sehingga mereka dapat menerapkannya di kehidupan nyata.

\section{UCAPAN TERIMA KASIH}

Ucapan terima kasih yang sebesar-besarnya kami haturkan kepada SMAK BPK Penabur Holis, Bandung atas 
kesempatannya yang kami peroleh untuk dapat melakukan kegiatan pengabdian kepada masyarakat berupa pembekalan tentang pentingnya kualitas jasa bagi siswa/i kelas XI SMAK BPK Penabur Holis, Bandung. Terima kasih pula kepada Universitas Kristen Maranatha, Bandung terutama Program Studi Teknik Industri atas dukungannya dalam membantu terselenggaranya kegiatan ini.

\section{DAFTAR PUSTAKA}

[1] A. Arindiaty and M. Bernik, "Analisis Kualitas Jasa Dalam Meningkatkan Kepuasan Konsumen Di Baker Street Cafe Bandung," Jurnal Bisnis Terapan, vol. 1, no. 1, pp. 43-51, Jun. 2017.

[2] A. S. Lubis and R. N. Andayani, "Pengaruh Kualitas Pelayanan (Service Quality) Terhadap Kepuasan Pelanggan PT. Sucofindo Batam," Journal of Business Administration, vol. 1, no. 2, pp. 232243, 2017.

[3] V. A. Zeithaml, M. J. Bitner, and D. D. Gremler, Services Marketing: Integrating Customer Focus Across the Firm, 7th edition. McGraw Hill Education, 2018

[4] H. Rohaeni and N. Marwa, "Kualitas Pelayanan Terhadap Kepuasan Pelanggan," Jurnal Ecodemica, vol. 2, no. 2, pp. 312-318, 2018.

[5] I. Carialy Irawan, A. Dwijayanti, and P. Administrasi Bisnis, "Pengaruh Kualitas Pelayanan terhadap Kepuasan Pelanggan pada PT. Kartika Cipta Anugrah Bandung," 2020.

[6] L. Sholeha, S. Djaja, and J. Widodo, "Pengaruh Kualitas Pelayanan Terhadap Kepuasan Pelanggan Di AHASS Sumber Jaya Maha Sakti Kecamatan Rogojampi Kabupaten Banyuwangi," JURNAL PENDIDIKAN EKONOMI: Jurnal Ilmiah Ilmu Pendidikan, Ilmu Ekonomi dan Ilmu Sosial, vol. 12, no. 1, p. 15, Jan. 2018, doi: 10.19184/jpe.v12i1.6465.

[7] J. E. Panjaitan and A. L. Yuliati, "Pengaruh Kualitas Pelayanan Terhadap Kepuasan Pelanggan pada JNE Cabang Bandung," DeReMa Jurnal Manajemen, vol. 11, no. 2, pp. 265-289, 2016, [Online]. Available: www.jne.co.id

[8] A. T. Haryanto, S. N. Dewi, and B. S. Triono, "Pemasaran Dan Keunggulan Bersaing (Studi Perusahaan Finance di Wonogiri)," Pemasaran Dan Keunggulan Bersaing 115 JPSB, vol. 7, no. 2, pp. 115-123, 2019

[9] A. Setiawan, N. Qomariah, and H. Hermawan, "Pengaruh Kualitas Pelayanan Terhadap Kepuasan Konsumen," JSMBI (Jurnal Sains Manajemen Dan Bisnis Indonesia), vol. 9, no. 2, pp. 114-126, 2019.

[10] Dr. A. Chayomchai, "The Service Quality Management of the Fitness Center: The Relationship among 5 Aspects of Service Quality," International Journal of Current Science Research and Review, vol. 04, no. 06, Jun. 2021, doi: 10.47191/ijcsrr/V4-i6-05.

[11] Y. Wau, Anifah, and A. V. Zati, "Peranan Tenaga Pengajar (Dosen) Profesional Dalam Pembentukan Karakter Mahasiswa Untuk Peningkatan Kualitas Pembelajaran Di Program Studi Pendidikan Luar Sekolah," Jurnal Keluarga Sehat Sejahtera, vol. 15, no. 1, pp. $70-84,2017$. 